\title{
Skeletal Muscle Protein and Amino Acid Metabolism in Experimental Chronic Uremia in the Rat
}

\author{
ACCELERATED ALANINE AND GLUTAMINE FORMATION AND RELEASE
}

\author{
Alan J. GaRber, Division of Endocrinology and Metabolism, Departments of \\ Medicine and Cell Biology, Baylor College of Medicine, Houston, Texas 77030
}

A B S T RACT The kinetics and factors regulating alanine and glutamine formation and release were investigated in skeletal muscle preparations from control and experimentally uremic rats. These preparations maintained phosphocreatine and ATP levels in vitro which closely approximated levels found in vivo. Alanine and glutamine release from uremic muscle were increased 45.8 and $36.0 \%$, respectively, but tissue levels were unaltered. The increased release of alanine by uremic muscle was not accounted for by decreased rates of medium alanine reutilization via oxidation to $\mathrm{CO}_{2}$ or incorporation into muscle protein. The maximal capacity of added amino acids such as aspartate, cysteine, leucine, and valine to stimulate net alanine and glutamine formation was the same in uremic and control muscle. Epitrochlearis preparations were partially labeled in vivo with [guanido- ${ }^{14} \mathrm{C}$ ]arginine. On incubation, preparations from uremic animals showed a $54.6 \%$ increase in the rate of loss of ${ }^{14} \mathrm{C}$-label in acid precipitable protein. Correspondingly, these same uremic preparations showed a $62.7 \%$ increase in ${ }^{14} \mathrm{C}$-label appearance in the acid-soluble fraction of muscle and in the incubation media. Insulin decreased alanine and glutamine release to an extent threefold greater in uremic than in control preparations, and increased muscle glucose uptake approximately threefold in all preparations. Although basal rates of $\left[4,5-{ }^{3} \mathrm{H}\right]$ leucine incorporation into protein were decreased $25 \%$ in uremic muscles as compared with control muscles, insulin stimulated $\left[{ }^{3} \mathrm{H}\right]$ leucine incorporation nearly equally in both preparations.

This paper was presented in part at the Annual Meeting of the Southern Society for Clinical Investigation, New Orleans, January, 1977.

Dr. Garber is an investigator of the Howard Hughes Medical Institute.

Received for publication 28 February 1977 and in revised form 24 April 1978.
These data demonstrate increased alanine and glutamine production and release from skeletal muscle of chronically uremic rats. This increase appears to derive in part from an enhancement of net protein degradation which could be caused by an acceleration in the breakdown of one or more groups of muscle proteins, or by an inhibition of protein synthesis, or by both processes. The increased alanine and glutamine formation and release in uremia appears not to result from an insensitivity to insulin action. The implications of these findings for an understanding of the abnormal carbohydrate metabolism of uremia are discussed.

\section{INTRODUCTION}

Diverse alterations of blood amino acid levels have been described in uremic patients maintained on hemodialysis (1-12). Amino acids such as glutamate, serine, and the branched-chain amino acids appeared to be increased $30-50 \%$ in anephric patients, compared to normal volunteers $(12-15)$, whereas other amino acids such as glutamine, citrulline, glycine, and the methyl histidines were substantially increased in uremic subjects (12-16). Although blood levels of other amino acids such as aspartate, threonine, histidine, and particularly alanine were found to be unchanged, plasma levels of alanine, aspartate, and threonine were increased in anephric subjects (12-16). Recently we observed a patient with chronic uremia and episodes of spontaneous hypoglycemia in whom hypoalaninemia and decreased rates of gluconeogenesis from alanine were found to account, at least in part, for the pathogenesis of the hypoglycemia (17). Accordingly, we have investigated the kinetics of alanine formation and release in isolated intact epitrochlearis skeletal muscle preparations obtained from rats made experimentally uremic by unilateral nephrectomy and segmental infarction of the contra- 
lateral kidney. Portions of this study have been presented previously (18) and have appeared in abstract form $(19,20)$.

\section{METHODS}

Adenylate kinase (EC 2.7.4.3), alanine aminotransferase (EC 2.6.1.2), creatine phosphokinase (EC 2.7.3.2), glucose6-phosphate, dehydrogenase (EC 1.1.1.49), glutamate dehydrogenase (EC 1.4.1.3), glutaminase (EC 3.5.1.2), hexokinase (EC 2.7.1.1), lactate dehydrogenase (EC 1.1.1.27), $\mathrm{NAD}^{+}$, $\mathrm{NADH}, \mathrm{NADP}^{+}$, ATP, ADP, glucose, pyruvate, and amino acids were obtained from the Sigma Chemical Co. (St. Louis, Mo.). $\left[\right.$ guanido $-{ }^{14} \mathrm{C}$ ]arginine (sp act $=55.3 \mathrm{mCi} / \mathrm{mmol}$ ) was from Amersham/Searle Corp. (Arlington Heights, Ill.), $\left[\mathrm{U}-{ }^{14} \mathrm{C}\right]$ alanine and $\left[4,5-{ }^{3} \mathrm{H}\right]$ leucine were purchased from New England Nuclear (Boston, Mass.). Crystalline glucagon-free insulin was a gift of Dr. J. Galloway (Eli Lilly and Co., Indianapolis, Ind.).

For studies of muscle metabolism in vitro, Sprague-Dawley rats weighing from 125 to $150 \mathrm{~g}$ were sacrificed by a blow to the high cervical spine. Epitrochlearis skeletal muscle preparations of the upper extremities were visualized and rapidly removed intact as described previously (21). Excess connective tissue was trimmed, and the muscle was rinsed briefly in isotonic sodium chloride, blotted, and placed in $0.5 \mathrm{ml}$ of a modified Krebs-Henseleit buffer ( $\mathrm{pH}$ 7.4), containing one-half the calcium concentration as originally formulated, and with increased buffering capacity produced by the addition of $5 \mathrm{mM} \mathrm{N}$-2-hydroxyethylpiperazine- $N^{\prime}$ 2-ethane sulfonic acid. Other additions to the medium such as amino acids, glucose, and insulin were as indicated. The incubation flasks were gassed with $95 \% \mathrm{O}_{2}-5 \% \mathrm{CO}_{2}$, stoppered, and incubations were carried out in a shaking water bath at $37^{\circ} \mathrm{C}$ for between 30 and $360 \mathrm{~min}$. At the end of the incubation, the muscles were removed rapidly, briefly rinsed in cold buffer, blotted, and then frozen in liquid nitrogen. All muscle samples and incubation media were stored at $-80^{\circ} \mathrm{C}$. Frozen muscle preparations were weighed while being maintained at $-20^{\circ} \mathrm{C}$ and then rapidly homogenized in ice-cold $3 \mathrm{M}$ perchloric acid, and subsequently centrifuged at $4,500 \mathrm{~g}$ for $15 \mathrm{~min}$. The resulting supernatent was neutralized with a solution containing $3 \mathrm{M}$ potassium hydroxide, $0.4 \mathrm{M}$ imidazole, and $0.7 \mathrm{M}$ potassium chloride, and the potassium perchlorate precipitate was removed by further centrifugation (22). For studies of isotopically labeled amino acid incorporation into protein in vitro, experiments were carried out in incubation flasks using continuous gassing with $95 \% \mathrm{O}_{2}-5 \% \mathrm{CO}_{2}$ for 1- to 6-h periods. The incubation medium was further modified by the addition of a mixture of 16 essential and nonessential amino acids (most at a 2.5-mM final concentration), and insulin at the indicated concentrations. $10 \mu \mathrm{Ci} / \mathrm{ml}$ of $\left[4,5^{-3} \mathrm{H}\right]$ leucine or $\left[\mathrm{U}-{ }^{14} \mathrm{C}\right]$ alanine was also added. After the incubation, labeled amino acid incorporation into protein was determined by homogenization of the frozen incubated muscle in hot $12 \%$ trichloroacetic acid with two subsequent washings of the acid insoluble pellet with $5 \%$ trichloroacetic acid, ether extraction, air drying, and solubilization of the pelleted precipitate with NCS solubilizer (Amersham Corp., Arlington Heights, Ill.). The latter was counted in a liquid scintillation spectrometer using ACS scintillant (Amersham Corp.). Studies of added [ $\mathrm{U}^{14} \mathrm{C}$ ] alanine oxidation by intact epitrochlearis preparations were carried out in sealed incubation flasks with injection stoppers and a bucket suspended above the media. Alanine was the only added amino acid (final concentration was $0.4 \mathrm{mM}$ ), and [U-14 $\mathrm{C}$ ]alanine was in- cluded at a $1-\mu \mathrm{Ci} / \mathrm{ml}$ final concentration. At the conclusion of the 1- to 4-h incubation period, the experiment was stopped by acidification of the incubation medium with $2 \mathrm{~N} \mathrm{H}_{2} \mathrm{SO}_{4}$, and $\left[{ }^{14} \mathrm{C}\right] \mathrm{CO}_{2}$ was trapped by subsequent absorption of the evolved $\left[{ }^{14} \mathrm{C}^{2} \mathrm{CO}_{2}\right.$ within the suspended bucket containing added triethanolamine base. The latter was then washed and transferred to liquid scintillation vials for counting using ScintiVerse (Fisher Scientific Co., Pittsburgh, Pa.) scintillant. Alanine-specific activities were determined from aliquots of the incubation medium before and after incubation.

For studies of protein labeling in vitro, epitrochlearis muscles were obtained from rats previously labeled in vivo using an initial intraperitoneal injection of $50 \mu \mathrm{Ci}$ [guanido${ }^{14} \mathrm{C}$ ]alanine $(\mathrm{Sp}$ act $=55 \mathrm{mCi} / \mathrm{mmol})$ followed $6 \mathrm{~h}$ later by a second intraperitoneal injection of $20 \mu \mathrm{mol}$ of unlabeled arginine. After $24 \mathrm{~h}$, the animals were sacrified, and epitrochlearis preparations were obtained and incubated for between 2 and $4 \mathrm{~h}$ in $0.5 \mathrm{ml}$ of Krebs-Henseleit buffer. After incubation, muscles were rinsed, blotted, and immediately frozen in liquid nitrogen. The tissues were subsequently homogenized in $0.9 \mathrm{ml}$ of hot $12 \%$ trichloroacetic acid and centrifuged for $20 \mathrm{~min}$ at $2,500 \mathrm{~g}$. The post-trichloroacetic acid supernate and the incubation medium were directly sampled for liquid scintillation counting. The precipitate in itself was washed twice with additional TCA and subsequently with diethyl ether with final air drying. This precipitate was dissolved in $0.2 \mathrm{ml}$ of NCS solubilizer and transferred to liquid scintillation vials and counted using ACS scintillant. Determinations of protein labeling in vivo using [guanido $-{ }^{14} \mathrm{C}$ ]arginine were carried out in a similar manner except that skeletal muscles were visualized after the animals had been anesthetized with pentobarbital. These muscles were quickly freeze-clamped in situ using Wollenberger tongs (Fisher Scientific Co.) previously chilled in liquid nitrogen. Isolation of trichloroacetic acid precipitable protein was followed as outlined above. Chronically uremic rats were produced surgically by unilateral nephrectomy and segmental infarction of the contralateral kidney after ligation of two of the renal arterial branches $(23,24)$. Supplemental feedings of casein, dextrose, and water were given. Control rats were pair-fed. Serum urea nitrogen was $59.1 \pm 6.8$ and $18.3 \pm 2.7 \mathrm{mg} / \mathrm{ml}($ mean $\pm \mathrm{SE})$ in the uremic and control groups, respectively.

Semimicro- and microfluorometric enzymatic techniques were used to determine levels of intermediates and substrates in perchloric acid extracts of skeletal muscle and in the incubation media. Glucose (22), lactate (25), ATP (22), ADP (22), phosphocreatine (22), alanine (26), aspartate, glutamate, and glutamine (25) were all assayed using coupled enzymatic assays linked to the appearance or disappearance of NADH or NADPH. Cyclic AMP was determined in trichloroacetic acid extracts of muscle by a sensitive, double-antibody radioimmunoassay (27). Statistical assessments were made using Student's $t$ test (28).

\section{RESULTS}

To determine the usefulness of the epitrochlearis preparation of rat skeletal muscle for in vitro studies of amino acid metabolism in experimental uremia, the effect of incubation was determined on adenine nucleotide and phosphocreatine levels in preparations obtained from chronically uremic and control rats. As shown in Table I, levels of ATP, ADP, and phosphocreatine in epitrochlearis preparations, which were freeze-clamped in situ, were not significantly 
TABLE I

Adenine Nucleotide and Phosphocreatine Levels in Muscle from Normal and Chronically Uremic Rats

\begin{tabular}{cccccc}
\hline Treatment & Preparation & ATP & ADP & Phosphocreatine & ATP/ADP \\
\hline \multirow{3}{*}{ Freeze-clamped, in situ } & & & \multicolumn{4}{c}{$\mu$ mol/g muscle, wet $w t$} \\
& Control & $4.87 \pm 0.25$ & $0.59 \pm 0.07$ & $15.6 \pm 1.09$ & $8.16 \pm 0.27$ \\
& Uremic & $4.82 \pm 0.21$ & $0.58 \pm 0.08$ & $14.7 \pm 0.71$ & $8.18 \pm 0.36$ \\
Incubation, in vitro & Control & $4.72 \pm 0.31$ & $0.66 \pm 0.12$ & $13.7 \pm 0.60$ & $7.21 \pm 0.68$ \\
& Uremic & $4.66 \pm 0.36$ & $0.61 \pm 0.05$ & $12.8 \pm 1.29$ & $7.32 \pm 0.73$ \\
\hline
\end{tabular}

Epitrochlearis preparations from chronically uremic and control rats were obtained and incubated in Krebs-Henseleit buffer ( $\mathrm{pH}$ 7.4) for $1 \mathrm{~h}$ as described in Methods. For comparison purposes, epitrochlearis preparations from the contralateral extremity of the same rat were freeze-clamped in situ using Wollenberger tongs previously cooled in liquid nitrogen. Using fluorometric microtechniques, levels of phosphocreatine, ATP and ADP were determined in the neutralized perchloric acid extracts of each muscle preparation. Values shown are the means $( \pm \mathrm{SEM})$ for at least six experiments.

different in the uremic animals as compared with the control animals, nor was there any difference in the ratio of ATP to ADP. Epitrochlearis preparations from the contralateral extremity of each animal were incubated for $1 \mathrm{~h}$. Levels of either ATP or ADP in incubated uremic preparations were not significantly altered compared with preparations freeze-clamped in situ. Taken as a whole, these data indicate that both preparations remained viable in vitro, and that there was no significant difference in muscle preparations from chronically uremic rats as compared with control rats.

An increased rate of release of most of the amino acids studied was found on incubation of skeletal muscle preparations from chronically uremic rats (Table II). With uremic muscle, alanine release was increased $46.8 \%(P<0.01)$, aspartate release was in-

TABLE II

Release of Alanine, Aspartate, Glutamate and Glutamine from Skeletal Muscle of Control and Chronically Uremic Rats

\begin{tabular}{cccccc}
\hline $\begin{array}{c}\text { Animal } \\
\text { treatment }\end{array}$ & $\begin{array}{c}\text { Alanine } \\
\text { release }\end{array}$ & $\begin{array}{c}\text { Aspartate } \\
\text { release }\end{array}$ & $\begin{array}{c}\text { Glutamate } \\
\text { release }\end{array}$ & $\begin{array}{c}\text { Glutamine } \\
\text { release }\end{array}$ & $\begin{array}{c}\text { Total } \\
\text { release }\end{array}$ \\
\hline$n$ nol/min per g muscle, wet wt
\end{tabular}

$\begin{array}{cccccc}\begin{array}{c}\text { Control } \\ \text { Chronic }\end{array} & 20.3 \pm 1.2 & 0.7 \pm 0.2 & 10.4 \pm 0.7 & 30.3 \pm 0.26 & 61.4 \pm 5.1 \\ \text { uremia } & 29.8 \pm 2.2 & 2.1 \pm 0.9 & 16.8 \pm 1.2 & 41.2 \pm 3.1 & 87.2 \pm 6.1\end{array}$

Epitrochlearis skeletal muscle preparations were obtained from control and chronically uremic rats. These preparations were placed in Krebs-Henseleit buffer and incubated for $1 \mathrm{~h}$. At the end of the incubation, muscles were removed, rinsed, blotted, frozen in liquid nitrogen, and extracted with perchloric acid. Alanine, aspartate, glutamate, and glutamine were determined enzymatically. Values shown for amino acids released are the means $( \pm$ SEM) for at least 14 experiments. creased $200 \%(P<0.05)$, glutamate release was increased $61.5 \%(P<0.02)$, glutamine release was increased $36.0 \%(P<0.02)$, and total amino acid release was increased $42.0 \%(P<0.02)$. Although rates of muscle alanine and glutamine release were increased in uremia, tissue levels of these two amino acids were not altered in uremic animals as compared with control animals (Table II). Epitrochlearis preparations from either uremic or control rats also showed no significant decrease in tissue amino acid levels in muscles that were freeze-clamped in situ (Table III). Taken together, the data of Tables II and III indicate an increased net formation of alanine and glutamine in skeletal muscle from chronically uremic rats.

\section{TABLE III}

Effect of Incubation on Levels of Alanine and Glutamine in Skeletal Muscle Preparations from Control and Chronically Uremic Rats

\begin{tabular}{|c|c|c|c|}
\hline $\begin{array}{c}\text { Animal } \\
\text { treatment }\end{array}$ & Treatment & $\begin{array}{c}\text { Alanine } \\
\text { level }\end{array}$ & $\begin{array}{c}\text { Glutamine } \\
\text { level }\end{array}$ \\
\hline \multirow{3}{*}{ Control } & & \multicolumn{2}{|c|}{ nmol/mg, wet weight } \\
\hline & $\begin{array}{l}\text { Freeze-clamped, } \\
\quad \text { in situ }\end{array}$ & $1.57 \pm 0.10$ & $3.51 \pm 0.24$ \\
\hline & Incubated & $1.51 \pm 0.13$ & $3.40 \pm 0.27$ \\
\hline \multirow[t]{2}{*}{$\begin{array}{l}\text { Chronic } \\
\text { uremia }\end{array}$} & $\begin{array}{l}\text { Freeze-clamped, } \\
\text { in situ }\end{array}$ & $1.62 \pm 0.11$ & $3.39 \pm 0.29$ \\
\hline & Incubated & $1.58 \pm 0.09$ & $3.28 \pm 0.21$ \\
\hline
\end{tabular}

Epitrochlearis preparations from chronically uremic and control rats were dissected and either freeze-clamped in situ or incubated in modified Krebs-Henseleit buffer. After incubation, muscles were rapidly removed from the media, rinsed, blotted, and frozen in liquid nitrogen. Alanine and glutamine were determined in the neutralized perchloric acid extracts of these muscles. Values given are the means $( \pm \mathrm{SEM})$ for at least six experiments. 
The metabolic basis for the increased release of alanine in skeletal muscle preparations of chronically uremic rats was next investigated. The effect of experimental uremia on pathways for reutilization of released alanine was studied in a separate series of experiments with $\left[\mathrm{U}-{ }^{14} \mathrm{C}\right] \mathrm{alanine}$ added to the incubation media (Table IV). $100 \mathrm{mU} / \mathrm{ml}$ insulin was also added to the incubation media to insure that $\left[{ }^{14} \mathrm{C}\right]$ alanine transport was not the major limiting step for $\left[{ }^{14} \mathrm{C}\right] \mathrm{CO}_{2}$ generation from extracellular alanine. The oxidation of $\left[\mathrm{U}_{-}{ }^{14} \mathrm{C}\right]$ alanine in the media to $\left[{ }^{14} \mathrm{C}\right] \mathrm{CO}_{2}$ by muscle preparations from control rats was relatively low and this rate was not substantially altered in muscles from chronically uremic rats. Similarly, the rate of uptake and incorporation from the media of $\left[\mathrm{U}-{ }^{14} \mathrm{C}\right]$ alanine into trichloroacetic acid precipitable protein by muscles from control rats was very small compared with the rate of net alanine release by control preparations. In preparations obtained from uremic rats, alanine incorporation into protein was unchanged compared with rates in control preparations at the concentration of insulin used.

The synthesis of alanine and glutamine can be stimulated in skeletal muscle by a number of added amino acids (29-32). However, it is unclear as to the mechanisms by which alanine and glutamine formation are stimulated by amino acids, such as leucine and cysteine, which do not appear to be metabolized

TABLE IV

Effect of Chronic Uremia on Alanine Utilization by Skeletal Muscle

\begin{tabular}{ccc}
\hline & \multicolumn{2}{c}{$\left[\mathrm{U}-{ }^{14} \mathrm{C}\right]$ Alanine } \\
\cline { 2 - 3 } Treatment & Oxidation to $\left[{ }^{14} \mathrm{C}\right] \mathrm{CO}_{2}$ & $\begin{array}{c}\text { Incorporation into } \\
\text { TCA-precipitable } \\
\text { protein }\end{array}$ \\
\hline
\end{tabular}

nmol/min/per g muscle, wet wt

Control

Chronic uremia

$0.155 \pm 0.064$

$0.173 \pm 0.012$

$0.606 \pm 0.086$

Epitrochlearis preparations from chronically uremic and control rats were obtained and incubated in Krebs buffer ( $\mathrm{pH}$ 7.4) containing $100 \mathrm{mU} / \mathrm{ml}$ insulin and $5 \mathrm{mM}$ glucose. In those experiments determining the rate of alanine oxidation, $10 \mu \mathrm{Ci} / \mathrm{ml} ; 0.4 \mathrm{mM}\left[\mathrm{U}-{ }^{14} \mathrm{C}\right.$ ] alanine was added to the incubation media, and for studies of alanine incorporation into protein, $1.0 \mu \mathrm{Ci} / \mathrm{ml} ; 0.4 \mathrm{mM}\left[\mathrm{U}-^{14} \mathrm{C}\right.$ ]alanine was added to the incubation media together with a mixture of 17 essential and nonessential amino acids. After incubation, the muscles were rapidly removed from the incubation media, rinsed, blotted, and homogenized in hot $12 \%$ TCA. The acid insoluble pellet was washed and subsequently counted in a liquid scintillation spectrometer. For calculations of alanine flux, mean alanine specific activities were determined after enzymatic analysis of the before and after incubation media. Values given are the means $( \pm S E M)$ for at least five experiments. to alanine or its precursors in muscle. To assess maximal capacities of alanine, glutamate, and glutamine formation in muscle from chronically uremic rats, amino acids such as aspartate, cysteine, leucine, and valine were added individually (10 $\mathrm{mM}$ each) to the incubation media and the rates of alanine, glutamate, and glutamine release were determined (Table V). Each of the amino acids studied increased the release of alanine and glutamine from skeletal muscle of uremic as well as control rats. Maximally stimulated rates of alanine and glutamine release by each added amino acid were not significantly different in uremic preparations as compared with control preparations.

Muscle proteins were partially labeled in vivo using pulse-chase administration of $50 \mu \mathrm{Ci}$ [guanido- ${ }^{14} \mathrm{C}$ ]arginine followed $6 \mathrm{~h}$ later by a second intraperitoneal injection of $20 \mu \mathrm{mol}$ of unlabeled arginine. $24 \mathrm{~h}$ after the injection of $\left[{ }^{14} \mathrm{C}\right]$ arginine label, equal amounts of label were found in vivo in the acid-precipitable protein fractions of skeletal muscle (Fig. 1). By $48 \mathrm{~h}$, the amount of ${ }^{14} \mathrm{C}$-label in trichloroacetic acid precipitable protein was less in muscle from uremic animals compared with control animals. However, the rate of decrease of protein-precipitable label after $24 \mathrm{~h}$ was nonlinear over the period studied. The

TABLE V

Effect of Added Amino Acids on Alanine, Glutamate, and Glutamine Release from Epitrochlearis Muscle Preparations of Normal and Chronically Uremic Rats

\begin{tabular}{lcccc}
\hline $\begin{array}{c}\text { Amino acid } \\
\text { added }\end{array}$ & $\begin{array}{c}\text { Animal } \\
\text { pretreatment }\end{array}$ & Alanine & $\begin{array}{c}\text { Glutamate } \\
\text { release }\end{array}$ & Glutamine \\
\hline \multirow{3}{*}{ None } & Control & $20.4 \pm 1.3$ & $10.6 \pm 1.0$ & $30.1 \pm 2.2$ \\
& Uremia & $28.2 \pm 1.4$ & $16.9 \pm 2.3$ & $39.1 \pm 2.3$ \\
Aspartate & Control & $53.5 \pm 4.2$ & $25.2 \pm 2.2$ & $37.4 \pm 2.3$ \\
& Uremia & $53.3 \pm 3.6$ & $27.3 \pm 2.3$ & $41.7 \pm 2.0$ \\
Cysteine & Control & $44.5 \pm 2.8$ & $10.0 \pm 1.3$ & $41.2 \pm 1.4$ \\
& Uremia & $42.8 \pm 3.4$ & $17.1 \pm 1.9$ & $42.5 \pm 2.6$ \\
Leucine & Control & $34.9 \pm 1.6$ & $10.9 \pm 1.1$ & $44.9 \pm 2.7$ \\
& Uremia & $37.2 \pm 0.9$ & $15.1 \pm 2.2$ & $47.0 \pm 2.6$ \\
Valine & Control & $37.0 \pm 2.1$ & $11.0 \pm 1.1$ & $45.4 \pm 2.3$ \\
& Uremia & $39.4 \pm 1.9$ & $16.8 \pm 2.0$ & $49.5 \pm 4.2$ \\
\hline
\end{tabular}

Epitrochlearis preparations were obtained from chronically uremic and control rats were incubated in Krebs-Henseleit buffer containing $5 \mathrm{mM}$ glucose and $100 \mathrm{mU} / \mathrm{mg}$ insulin. To this incubation media, aspartate, cysteine, leucine, or valine (10 $\mathrm{mM}$ each) were added singly. The release of alanine, glutamate, and glutamine in the incubation media were determined using fluorometric microtechniques. Values given are the means $( \pm \mathrm{SEM})$ for at least six experiments. 


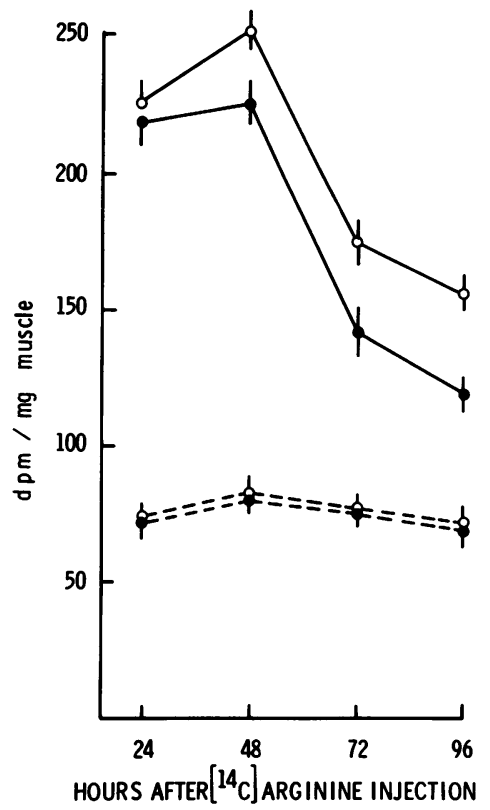

FIGURE 1 The incorporation of [guanido- ${ }^{14} \mathrm{C}$ ]arginine in skeletal muscle of control and chronically uremic rats. A $50-\mu \mathrm{Ci}$ intraperitoneal injection of [guanido- ${ }^{14} \mathrm{C}$ ] arginine was administered to control $(O)$, and chronically uremic rats (๑), $6 \mathrm{~h}$ later a $20-\mu \mathrm{mol}$ injection of unlabeled arginine was administered. After the $\left[{ }^{14} \mathrm{C}\right]$ arginine, animals were sacrificed and the radioactivity was determined in the acid soluble $(\mathrm{O}---\mathrm{O})$ and acid insoluble $(\mathrm{O}-\mathrm{O})$ fractions of muscle as described in Methods. Values shown are the means $( \pm \mathrm{SEM})$ for at least 12 experiments.

decrement in ${ }^{14} \mathrm{C}$-labeling of protein in uremic muscle appeared to be accentuated with an increasing period between the time of the injection of $\left[{ }^{14} \mathrm{C}\right]$ arginine label and the time of sampling of muscle. Experi- ments were then performed in vitro to assess the rate of clearance of ${ }^{14} \mathrm{C}$-label in endogenous skeletal muscle proteins in uremia. Using similar pulse-chase isotope labeling protocols, epitrochlearis preparations from control and chronically uremic rats were obtained in which partial labeling of at least some proteins with [guanido- ${ }^{14} \mathrm{C}$ ] arginine had been produced. Muscles were isolated $24 \mathrm{~h}$ after the injections. After sacrifice of the animals, muscles of one extremity were dissected and incubated and muscles from the other extremity were freeze-clamped in situ (Table VI). Labeling of acid-precipitable protein in freezeclamped muscles was similar in both control and uremic animals. On incubation, the amount of acidprecipitable ${ }^{14} \mathrm{C}$-label decreased and this increased $62.7 \%(P<0.05)$ in muscles of uremic animals as compared with control animals. Similarly, there were proportional increments in nonprecipitable ${ }^{14} \mathrm{C}$-label. Total nonprecipitable ${ }^{14} \mathrm{C}$-label was increased on incubation $55 \%$ with uremic muscle $(P<0.05)$, from 18.5 $\pm 2.3 \mathrm{dpm} / \mathrm{mg}$ muscle with control preparations, to 28.6 $\pm 2.5 \mathrm{dpm} / \mathrm{mg}$ muscle with uremic preparations.

Because insulin insensitivity or resistance has been postulated in chronic uremia (33-38), the effects of added insulin were studied on muscle alanine and glutamine formation, and release in uremia. As shown in Figs. 2 and 3, increasing concentrations of insulin were associated with an $\cong 10 \%$ decrease in the rate of alanine and glutamine release from control preparations, but with preparations from chronically uremic rats, insulin produced a $30 \%$ suppression of amino acid release. Tissue levels of alanine and glutamine were unaltered. Significant suppression of amino acid release was observed with insulin concentrations of $\cong 1-10 \mathrm{mU} / \mathrm{ml}$ in uremic preparations. Adrenergic

TABLE VI

Effect of Incubation on the Distribution of $\left[{ }^{14} \mathrm{C}\right]$ Arginine in Skeletal Muscle from Normal and Chronically Uremic Rats Previously Labeled in vivo

\begin{tabular}{|c|c|c|c|c|c|c|}
\hline \multirow[b]{2}{*}{ Treatment } & \multicolumn{2}{|c|}{ Muscle TCA } & \multirow{2}{*}{$\begin{array}{l}\text { Released } \\
\text { to media }\end{array}$} & \multirow{2}{*}{$\begin{array}{c}\text { Total } \\
\text { nonprecipitable } \\
\text { label }\end{array}$} & \multirow{2}{*}{$\begin{array}{c}\text { Increment in } \\
\text { nonprecipitable } \\
\text { label after incubation }\end{array}$} & \multirow{2}{*}{$\begin{array}{c}\text { Decrement in } \\
\text { precipitable } \\
\text { label after incubatio }\end{array}$} \\
\hline & Insoluble & Soluble & & & & \\
\hline & & & & n/mg muscle, wet & & \\
\hline \multicolumn{7}{|l|}{ Control } \\
\hline Frozen, in situ & $227.2 \pm 7.5$ & $67.4 \pm 5.2$ & - & $67.4 \pm 5.2$ & - & - \\
\hline Incubated & $209.5 \pm 5.9$ & $32.8 \pm 2.4$ & $53.4 \pm 5.3$ & $85.9 \pm 4.9$ & $18.5 \pm 1.4$ & $17.7 \pm 1.6$ \\
\hline \multicolumn{7}{|l|}{ Uremic } \\
\hline Frozen, in situ & $221.6 \pm 9.4$ & $73.2 \pm 5.0$ & - & $73.2 \pm 5.0$ & - & - \\
\hline Incubated & $192.8 \pm 7.9$ & $35.6 \pm 1.4$ & $66.3 \pm 5.9$ & $101.8 \pm 5.8$ & $28.6 \pm 2.0$ & $28.8 \pm 2.3$ \\
\hline
\end{tabular}

Control and chronically uremic rats were injected with $50 \mu \mathrm{Ci}$ [guanido- ${ }^{14} \mathrm{C}$ ]arginine, followed $6 \mathrm{~h}$ later by $20 \mu \mathrm{mol}$ of unlabeled arginine. $24 \mathrm{~h}$ later, epitrochlearis preparations were obtained and incubated. Preparations from the contralateral extremity were immediately freeze-clamped in situ. At the conclusion of the 2-h incubation, preparations were removed, frozen in liquid nitrogen, homogenized in $12 \%$ trichloroacetic acid, and the acid insoluble pellet washed and subsequently solubilized. Samples of the incubation media, the acid soluble extract of skeletal muscle, and of the acid insoluble pellet were counted in a liquid scintillation spectrometer. Values shown below are the means $( \pm$ SEM) for at least eight experiments. 


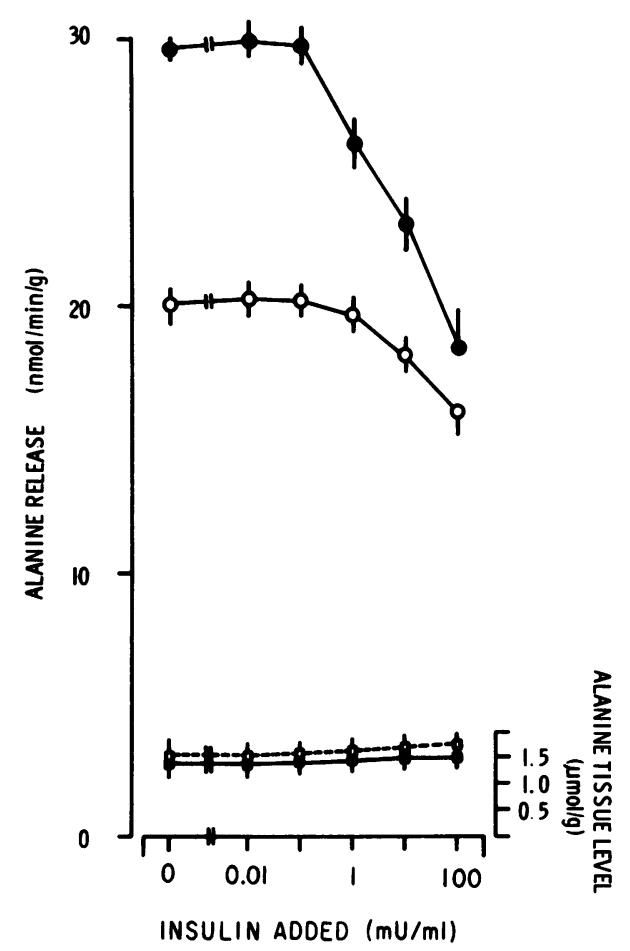

FIGURE 2 The effects of added insulin on alanine release and tissue levels in skeletal muscle of chronically uremic and control rats. Epitrochlearis preparations were obtained from chronically uremic $(O)$ and control $(O)$ rats and were incubated as described in detail in Methods in modified KrebsHenseleit buffer ( $\mathrm{pH}$ 7.4) containing crystalline glucagonfree pork insulin added to a final concentration as indicated. After a 1-h incubation, alanine was determined in the media using enzymatic techniques. Values shown for alanine release are the means $( \pm \mathrm{SEM})$ for at least six experiments. Tissue levels of alanine were determined in acid extracts of muscle. Values shown are the means $( \pm S E M)$ for at least six experiments.

agonists inhibit alanine and glutamine formation and release in skeletal muscle $(39,40)$. The extent of this inhibition has been shown to be generally proportional to the increments in muscle cAMP levels produced by $\beta$-adrenergic agonists. Accordingly, the influence of exogenous insulin on steady-state levels of cAMP in skeletal muscle of chronically uremic and control animals was also determined. A variety of incubation periods ranging between 2 and $60 \mathrm{~min}$ were investigated. Increasing concentrations of insulin caused no significant alteration of steady-state cAMP levels in skeletal muscle preparations from either control or chronically uremic animals.

Other actions of insulin on skeletal muscle metabolism in uremia were also investigated. As shown in Fig. 4, exogenous insulin produced a threefold increase in the rate of glucose uptake by skeletal muscle preparations from control animals. In preparations obtained from chronically uremic animals, basal rates of glucose uptake were $\cong 50 \%$ greater than rates obtained in preparations from control animals ( $P$ $<0.05$ ), and insulin produced a proportionally greater increase in the rate of glucose uptake in uremic muscles as compared with control muscles. At each concentration of exogenous insulin studied, rates of insulin-stimulated glucose uptake were 50-100\% greater in uremic muscle as compared with control muscle. Other insulin-stimulated processes in muscle, such as protein synthesis, were also studied (Fig. 5). Basal rates of $\left[4,5-{ }^{3} \mathrm{H}\right]$ leucine incorporation into trichloroacetic acid precipitable protein were decreased $\cong 25 \%$ in muscle from uremic animals as compared with control animals $(P<0.02)$. With increasing concentrations of insulin, rates of leucine incorporation increased in both uremic and control preparations. At the lower concentrations of insulin studied $(1-100 \mathrm{mU} / \mathrm{ml})$, protein synthesis rates in uremic muscles remained somewhat lower than in control muscles. But, at the higher insulin levels studied $(0.1-1 \mathrm{U} / \mathrm{ml})$, rates of protein synthesis were equal with both preparations. In parallel studies, intracellular leucine pool size was found not to be significantly different in uremic preparations as compared with control preparations, either before or after incubation. Calculated intracellular leucine specific

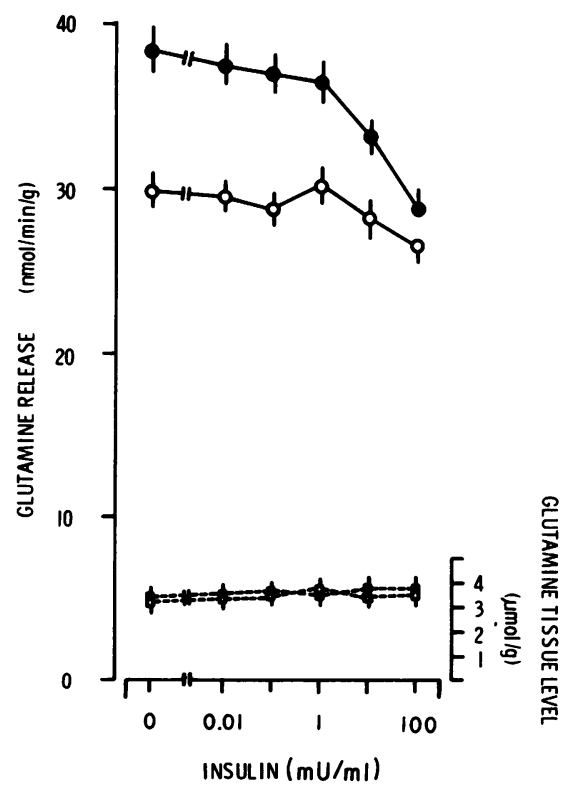

FIGURE 3 The effect of added insulin on glutamine release and tissue levels in skeletal muscle of chronically uremic and control rats. Epitrochlearis preparations were obtained from chronically uremic $(O)$ and control $(O)$ rats and were incubated for $1 \mathrm{~h}$ as detailed in Methods with crystalline glucagon-free pork insulin at concentrations indicated. The values shown are the means $( \pm \mathrm{SEM})$ for at least six experiments. 


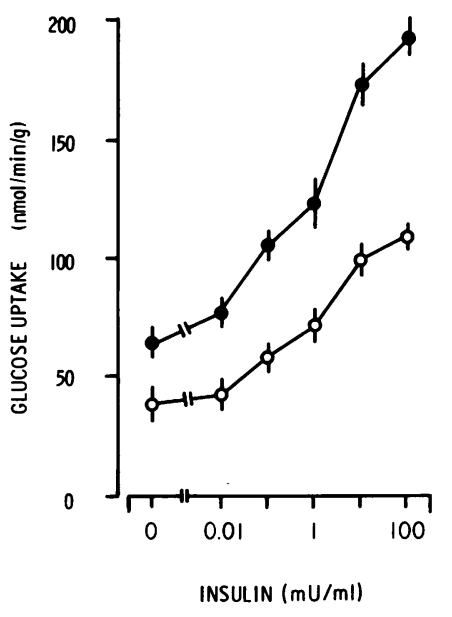

FIGURE 4 The effect of exogenous insulin on glucose uptake by skeletal muscle from control and chronically uremic rats. Epitrochlearis preparations from control $(O)$ and chronically uremic $(O)$ rats were obtained and incubated at $37^{\circ} \mathrm{C}$ for $1 \mathrm{~h}$ in a modified Krebs-Henseleit buffer containing $5 \mathrm{mM}$ glucose, and insulin added to the concentrations indicated. As described in Methods, glucose concentrations were determined in the media before and after incubation. Glucose uptake was calculated by difference and the values shown are the means $( \pm$ SEM $)$ for at least eight experiments.

activities were not different in the preparations studied.

\section{DISCUSSION}

The isolated intact epitrochlearis preparation of rat skeletal muscle, which we have described previously $(21,31,32,29)$, appears to provide an excellent model system for in vitro studies of potential derangements of muscle metabolism in uremia. A broad range of metabolic criteria were used to determine the suitability of the epitrochlearis preparation for in vitro studies of skeletal muscle metabolism, including $(a)$ maintenance of linear rates of protein synthesis for periods up to 6-h duration, $(b)$ a substantial facilitation by exogenous insulin of muscle glucose uptake, and $(c)$ the preservation on incubation of muscle phosphocreatine and ATP levels which closely approximate those levels found in muscles freeze-clamped in vivo. Phosphocreatine and ATP levels in the incubated muscle preparations were approximately equal to levels observed in skeletal muscles of uremic animals freeze-clamped in situ (Table I), and insulin facilitation of glucose uptake was readily apparent (Fig. 4). Using these criteria, we can therefore conclude that the epitrochlearis preparation is a suitable model for studies of skeletal muscle metabolism in chronic uremia.

Although epitrochlearis preparations from chronically uremic rats demonstrated an increased rate of release of all amino acids studied, the observed in-

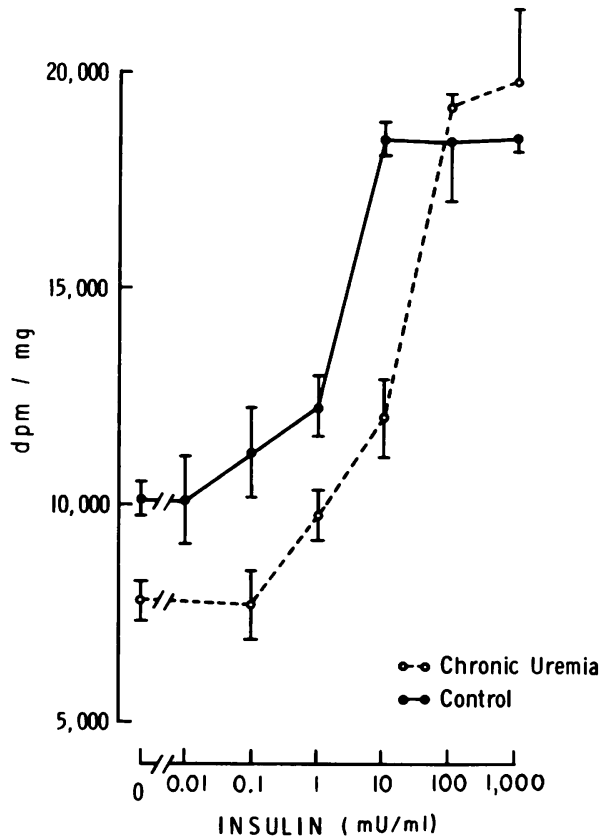

FIgURE 5 The effect of insulin on $\left[4,5-{ }^{3} \mathrm{H}\right]$ leucine incorporation into protein in skeletal muscle of control and chronically uremic rats. Epitrochlearis preparations from control $(O)$ and chronically uremic $(O)$ rats were obtained and incubated with $10 \mu \mathrm{Ci}\left[4,5-{ }^{3} \mathrm{H}\right]$ leucine and insulin at the concentrations indicted as detailed in Methods. Protein was isolated from trichloroacetic acid homogenates, washed, solubilized, and counted. Values shown are the means ( \pm SEM) for at least five experiments and are expressed as dpm of ${ }^{3} \mathrm{H}$ label incorporated per milligram muscle, wet weight.

creases in alanine and glutamine release were quantitatively the most substantial (Table II). This increased release of alanine and glutamine appears to result from an increased net formation of these two amino acids in uremic muscle because tissue levels of alanine and glutamine were essentially unaltered with incubation as compared with levels observed in muscle freezeclamped in situ. These levels in uremic muscle were virtually identical to levels observed in muscle of control rats (Table III, Fig. 3). Although it is possible that uremia might induce compensatory decreases in pathways of muscle alanine reutilization which were not detected in studies with $\mathrm{U}_{-14}{ }^{14} \mathrm{C}$ added to the media (Table IV), it seems more reasonable to conclude that the increased rates of alanine and glutamine release from skeletal muscle of uremic rats derive primarily from an increased formation of these two amino acids.

The stimulation of alanine and glutamine formation by a variety of amino acids has been well documented in a number of different rat skeletal muscle preparations (31-33), although the precise mechanism for this stimulation has not been established. The rate of alanine and glutamine formation in muscle has been related to the rate at which endogenous skeletal mus- 
cle proteins are degraded, because it is the latter process which in part maintains the availability of endogenous amino acids for alanine and glutamine formation within the muscle cell (32). The observations of the present study on alanine and glutamine formation and release in skeletal muscle of chronically uremic animals suggest that the enhanced rate of alanine and glutamine formation in uremia may derive from an accelerated net protein degradation which may be caused by an increased breakdown of one or more classes of endogenous skeletal muscle proteins, or by an inhibition of protein synthesis, or both. Support for this conclusion is provided by the finding that the stimulated rates of alanine and glutamine formation produced by added amino acids were not substantially enhanced in uremic muscle as compared with control muscle (Table V). Because the maximum capacity of uremic skeletal muscle to form alanine and glutamine may not be altered, it seems possible that an increased availability of amino acids may be an important regulatory factor accounting for the increased alanine and glutamine formation in uremia. Experiments in which at least some of the proteins of the epitrochlearis preparations were partially labeled with [guanido $-{ }^{14} \mathrm{C}$ ]arginine in vivo suggest that an accelerated net degradation can also be observed in uremic skeletal muscle incubated in vitro (Table VI). Additionally, patterns of ${ }^{14} \mathrm{C}$-labeling of muscle protein in vivo with [guanido${ }^{14} \mathrm{C}$ ]arginine also suggest either enhanced pattern degradation or diminished protein synthesis or both in uremic animals (Fig. 1). As a consequence of either or both effects, the resultant increase in the availability of amino acids for alanine and glutamine formation may account in part for the increased rate of alanine and glutamine formation in skeletal muscle of uremic animals.

The precise biochemical pathogenesis for the increased muscle alanine and glutamine formation and release in uremia is not fully explained by the results of this study. Insulin has been shown to be a major hormonal factor modulating protein synthesis and protein degradation in skeletal muscle. Insensitivity or resistance to the metabolic actions of insulin on peripheral tissues such as skeletal muscle have been postulated in uremia (33-38). For the most part, these conclusions derive from observations of hyperinsulinism and carbohydrate intolerance or even overt fasting hyperglycemia in patients with chronic uremia. That the phenomenon of insulin insensitivity or resistance appears not to account for the increased formation and release of alanine and glutamine is shown by the data of Figs. 2 and 3 . The extent of suppression of alanine and glutamine release by exogenous insulin was quantitatively greater in muscle from chronically uremic rats as compared with control rats. For example, the decrement produced in alanine release from uremic muscle at the highest concentration of insulin studied was more than threefold greater than the decrement produced with muscles from control rats. These findings of heightened insulin sensitivity in uremic muscle were not limited to insulin effects solely on amino acid release. Other aspects of muscle metabolism also appeared to retain normal sensitivity to exogenous insulin. For example, rates of insulin-stimulated glucose uptake by skeletal muscle from uremic animals were equal to or greater than rates observed in muscle from control rats, and the magnitude of the insulin stimulation was approximately equal in both preparations. On the other hand, insulin-stimulated leucine incorporation into protein did appear to show some element of diminished sensitivity to exogenous insulin (Fig. 5). In this instance, lower basal rates of protein synthesis were observed in muscle from chronically uremic rats, although maximally stimulated rates of amino acid incorporation into protein with high concentrations of insulin were equal in uremic and control muscles. It seems reasonable to infer from these data that a unitary mechanism solely involving abnormalities of insulin action cannot account for the observed derangements of muscle metabolism in uremia. Insofar as muscle protein and amino acid metabolism are concerned, disturbances of insulin action do not appear to account for data of this study.

The results of the present study have important implications for an understanding of the abnormal carbohydrate metabolism in patients with chronic uremia. Although virtually every abnormality of glucose homeostasis has been reported in uremia, carbohydrate intolerance and even overt fasting hyperglycemia are most frequently encountered (36). Hyperglycemia may be associated with abnormalities of hepatic gluconeogenesis. Alanine, the principal amino acid precursor for hepatic glucose production (41), is quantitatively the most important substrate other than lactate for hepatic gluconeogenesis. Alanine and glutamine account for the bulk of amino acids released by muscle (21). Studies performed in vitro using an isolated perfused liver model for hepatic gluconeogenesis have demonstrated that uremia is associated with an increased maximal capacity for hepatic glucose production from amino acids $(42,43)$. Because studies performed in vivo as well as in vitro have demonstrated that the rate of alanine delivery can be rate limiting for gluconeogenesis $(7,44)$, the findings of the present study demonstrating an increased rate of alanine production and release from skeletal muscle in uremia, suggest that an increased rate of hepatic gluconeogenesis from alanine may indeed occur in vivo. Thus, accelerated gluconeogenesis in liver and accelerated substrate delivery from skeletal muscle may be combined to produce a chronically expanded blood glucose pool in uremia. In support of this concept, it should be 
noted that increased hepatic gluconeogenesis, together with an increased rate of alanine delivery from skeletal muscle, have been observed in other hyperglycemic states such as diabetes mellitus $(32,45,46)$.

\section{ACKNOWLEDGMENTS}

We are indebted to Jannie Corbin, Yael Harari, Carol Maillet, and Nurit Shimoni for their excellent technical assistance. The advice and commentary of Dr. Wadi Suki and Dr. Lutz Birnbaumer are gratefully acknowledged.

These studies were supported, in part, by contract NO1-AM-4-2215 from the Artificial Kidney-Chronic Uremia Program of the National Institute of Arthritis, Metabolism, and Digestive Disease and by a grant from the Muscular Dystrophy Association of America.

\section{REFERENCES}

1. Ginn, H. E., A. Frost, and W. W. Lacy. 1968. Nitrogen balance in hemodialysis patients. Am. J. Clin. Nutr. 21: 385-393.

2. Aviram, A., J. H. Peters, and P. F. Gulyassy. 1971. Dialysance of amino acids and related substances. Nephron. 8: 440-454.

3. Kopple, J. D., M. E. Swendseid, J. H. Sinaberger, and C. Y. Umezawa. 1973. The free and bound amino acids removed by hemodialysis. Trans. Am. Soc. Artif. Intern. Organs. 19: 309-313.

4. Kopple, J. D., and M. E. Swendseid. 1975. Evidence that histidine is an essential amino acid in normal and chronically uremic man. J. Clin. Invest. 55: 881-891.

5. Giordano, C., M. Pluvio, and R. Esposito. 1975. Urea index and nitrogen balance in uremic patients on minimal nitrogen intakes. Clin. Nephrol. 3: 168-171.

6. Walser, M. 1975. Ketoacids in treatment of uremia. Clin. Nephrol. 3: 180-186.

7. Bergstrom, J., P. Furst, and L. O. Noree. 1975. Treatment of chronic uremic patients with protein-poor diet and oral supply of essential amino acids. I. Nitrogen balance studies. Clin. Nephrol. 3: 188-194.

8. Noree, L. O., and J. Bergstrom. 1975. II. Clinical results of long-term treatment. Clin. Nephrol. 3: 195-203.

9. Giordano, C., C. DePascale, H. Pluvio, N. H. DeSanto, A. Fella, R. Esposito, G. Capasso, and A. Pota. 1975. Adverse effects among amino acids in uremia. Kidney Int. 7(Suppl.): S306-S310.

10. Aronson, A. S., P. Furst, B. Kuglenstierna, and G. Nyberg. 1975. Essential amino acids in the treatment of advanced uremia. Twenty-two months experience in a 5 year old girl. Pediatrics. 56: 538-542.

11. Kopple, J. D., and H. E. Swenseid. 1975. Protein and amino acid metabolism in uremic patients undergoing maintenance hemodialysis. Kidney Int. 7(Suppl. 2): S64-S72.

12. Ganda, O. P., T. T. Aoki, J. S. Soeldner, R. S. Morrison, and G. F. Cahill, Jr. 1976. Hormone-fuel concentrations in anephric subjects. Effects of hemodialysis (with special reference to amino acids). J. Clin. Invest. 57: 1403-1411.

13. Giordano, C., C. DePascale, D. DeCristofaro, G. Capodicasa, C. Balestrieri, and K. Baczyk. 1968. Protein malnutrition in the treatment of chronic uremia. In Nutrition in Renal Disease. G. M. Berlyne, editor. The Williams \& Wilkins Co., Baltimore. 23.

14. Gulyassy, P. F., A. Aviram, and J. H. Peters. 1970. Evaluation of amino acid and protein requirements in chronic uremia. Arch. Intern. Med. 126: 855-859.
15. Peters, J. H., P. F. Hulyassy, S. C. Lim, P. M. Ryan, B. J. Berridge, W. R. Chao, and J. B. Cummings. 1968. Amino acid patterns in uremia: Comparative effects of hemodialysis and transplantation. Trans. Am. Soc. Artif. Intern. Organs. 14, 405-410.

16. Condon, J. R., and A. M. Asatoor. 1971. Amino acid metabolism in uraemic patients. Clin. Chim. Acta. 32: 333-337.

17. Garber, A. J., D. M. Bier, P. E. Cryer, and A. S. Pagliara. 1974. Hypoglycemia in compensated chronic renal insufficiency. Substrate limitation of gluconeogenesis. Diabetes. 23: 982-986.

18. Garber, A. J. 1976. Ninth Annual Contractors Conference, Artificial Kidney-Chronic Uremia Program. National Institute of Arthritis, Metabolism, and Digestive Diseases, National Institutes of Health. 5-8.

19. Garber, A. J. 1976. Alanine and glutamine release from skeletal muscle in chronic uremia. Clin. Res. 24: 360A. (Abstr.)

20. Garber, A. J. 1977. Skeletal muscle alanine and glutamine formation and release in experimental uremia. Clin. Res. 25: 32A. (Abstr.)

21. Garber, A. J., I. E. Karl, and D. M. Kipnis. 1976. Alanine and glutamine synthesis and release from skeletal muscle. I. Glycolysis and amino acid release. J. Biol. Chem. 251: 826-835.

22. Lowry, O. H., and J. V. Passonneau. 1972. A Flexible Enzymatic Analysis. Academic Press, Inc., New York.

23. Avioli, L. V., S. Scott, S. W. Lee, and H. F. DeLuca. 1969. Intestinal calcium absorption: Nature of defect in chronic renal disease. Science (Wash. D. C.). 166: 1154-1155.

24. Russell, J. E., and L. V. Avioli. 1972. Effect of experimental chronic renal insufficiency in bone mineral and collagen maturation. J. Clin. Invest. 51: 3072-3079.

25. Hohorst, H. J. 1965. In Methods in Enzymatic Analysis. H. V. Bergmeyer, editor. Academic Press, Inc., New York. 266-270.

26. Karl, I. E., A. S. Pagliara, and D. M. Kipnis. 1972. A microfluorometric enzymatic assay for the determination of alanine and pyruvate in plasma and tissue. J. Lab. Clin. Med. 80: 434-441.

27. Steiner, A. L., C. W. Parker, and D. M. Kipnis. 1972. Radioimmunoassay for cyclic nucleotides. J. Biol. Chem. 247: 1106-1113.

28. Snedecor, G. W., and W. G. Cochran. 1967. Statistical Methods. Iowa State University Press, Ames, Sixth edition. 257.

29. Ruderman, N. B., and M. Berger. 1974. The formation of glutamine and alanine in skeletal muscle. J. Biol. Chem. 249: 5500-5506.

30. Goldstein, L., and E. A. Newsholme. 1976. The formation of alanine from amino acids in diaphragm muscle of the rat. Biochem. J. 154: 555-558.

31. Garber, A. J., I. E. Karl, and D. M. Kipnis. 1976. Alanine and glutamine synthesis and release from skeletal muscle. II. The precursor role of amino acids in alanine and glutamine synthesis. J. Biol. Chem. 251: 836-843.

32. Karl, I. E., Garber, A. J., and D. M. Kipnis. 1976. Alanine and glutamine synthesis and release from skeletal muscle. III. Dietary and hormonal regulation. J. Biol. Chem. 251: 844-850.

33. Bilbrey, G. L., G. R. Faloona, M. G. White, and J. P. Knochel. 1974. Hyperglucagonemia of renal failure. $J$. Clin. Invest. 53: 841-847.

34. Swenson, R. S., J. Weisinger, and G. M. Reaven. 1974. Evidence that hemodialysis does not improve the glucose tolerance of patients with chronic renal failure. Metab. Clin. Exp. 23: 929-936. 
35. Hampers, C. L., E. G. Lowrie, J. S. Soeldner, and J. P. Merrill. 1970. The effect of uremia upon glucose metabolism. Arch. Intern. Med. 126: 870-874.

36. DeFronzo, R. A., R. Andres, P. Edgar, and W. G. Walker. 1973. Carbohydrate metabolism in uremia: a review. Medicine (Baltimore). 52: 469-497.

37. Weisinger, J., R. S. Swenson, W. Greene, J. B. Taylor, and G. M. Reaves. 1972. Comparison of the effects of metabolic acidosis and acute uremia on carbohydrate tolerance. Diabetes. 21: 1109-1115.

38. Nitzan, M. 1973. Abnormalities of carbohydrate and lipid metabolism in experimentally induced uremia. J. Nutr. Metabol. 15: 187-191.

39. Garber, A. J., I. E. Karl, and D. M. Kipnis. 1976. Alanine and glutamine synthesis and release from skeletal muscle. IV. -adrenergic inhibition of amino acid release. $J$. Biol. Chem. 251: 851-857.

40. Li, J. B., and L. S. Jefferson. 1975. Effects of isoproterenol on protein turnover and amino acid release in perfused skeletal muscle. Diabetes. 24(Suppl. 2): 93A. (Abstr.)

41. Felig, P., O. E. Owen, J. Wahren, and G. F. Cahill, Jr.
1969. Amino acid metabolism during prolonged starvation. J. Clin.Invest. 48: 584-592.

42. Maier, K. P., G. Hoppe-Seyler, H. Talke, J. Frohlich, P. Schollmeyer, and W. Gerok. 1973. Enzymatic and metabolic studies on carbohydrate and amino acid metabolism in rat liver during acute uremia. Eur. J. Clin. Invest. 3: 201-207.

43. Frohlich, J., J. Scholmerich, G. Hoppe-Seyler, K. P. Maier, H. Talke, P. Schollmeyer, and W. Gerok. 1974. The effect of acute uremia on gluconeogenesis in isolated perfused rat livers. Eur. J. Clin. Invest. 4: 453-458.

44. Mallette, L. E., J. H. Exton, and C. R. Park. 1969. Control of gluconeogenesis from amino acids in the perfused rat liver. J. Biol. Chem. 244: 5713-4523.

45. Wahren, J., P. Felig, E. Cerasi, and R. Luft. 1972. Splanchnic and peripheral glucose and amino acid metabolism in diabetes mellitus. J. Clin. Invest. 51: 1870-1878.

46. Bowen, H. F., and J. A. Moorhouse. 1973. Glucose turnover and disposal in maturity-onset diabetes. J. Clin. Invest. 52: 3033-3045. 